\section{Cureus}

Received 03/28/2019

Review began 05/05/2019

Review ended 05/07/2019

Published 06/09/2019

\section{(C) Copyright 2019}

Stead et al. This is an open access article distributed under the terms of the Creative Commons Attribution License CC-BY 3.0., which permits unrestricted use, distribution, and reproduction in any medium, provided the original author and source are credited.

\title{
Knowledge, Awareness, and Attitudes Regarding Concussion Among Middle Schoolers
}

Thor S. Stead ${ }^{1}$, Yasamin Daneshvar ${ }^{2}$, Sarah Ayala ${ }^{3}$, Latha Ganti ${ }^{4}$

1. Emergency Medicine, Alpert Medical School of Brown University, Providence, USA 2. Podiatry, New York College of Podiatric Medicine, New York, USA 3. Medical Education, Touro College of Osteopathic Medicine, Vallejo, USA 4. Emergency Medicine, Envision Physician Services, Orlando, USA

$\square$ Corresponding author: Latha Ganti, latha.ganti@ucf.edu

Disclosures can be found in Additional Information at the end of the article

\section{Abstract}

Introduction: Given the widespread prevalence of concussions in children under the age of 19, the adolescent perspective, as well as an understanding of the mechanisms behind traumatic brain injury (TBI), is extremely important. The authors sought to assess the knowledge, awareness, and attitudes regarding concussion among middle school children and whether a brief educational intervention based on clinical data and science resulted in a change of their knowledge or attitudes towards concussions.

Methods: A 20-question survey design was administered before and after an educational intervention. The surveys were anonymous, but they were paired so that it was possible to correlate the pre- and post-test answers to the respondents. An eighth-grader at a Florida middle school conducted this study after school hours after the student and their parent or legal guardian signed informed consent. This project was approved by the Science Department at Howard Bishop Middle School in Alachua County, Florida. JMP ${ }^{\circledR} 14.0$ (SAS Institute Inc., Cary, $\mathrm{NC}$ ) was used for statistical analyses.

Results: The cohort was 64\% female, age range: 13 - 15, and consisted of local eighth-grade students. Forty-three percent never wore a helmet when riding a bicycle or skateboard. Only $68 \%$ knew that the state had a helmet law for kids. Participants were significantly more likely to feel they had good TBI knowledge after the intervention ( $p=0.0005$, 95\% confidence interval (CI) 0.1937 to 0.6863 ) and that the didactic lectures changed the way they thought about safety ( $p=0.0034,95 \%$ CI 0.1025 to 0.5175 ). Students reported that their mothers (vs. fathers) were significantly more likely to wear seatbelts ( $p=0.05,95 \%$ CI 0.0036 to 0.5036 ), and they themselves reported wearing seatbelts more often after the survey.

Conclusions: There still exists a knowledge gap when it comes to pediatric concussion. Expanding awareness is important in order to bolster safety measures among adolescents.

Categories: Emergency Medicine, Pediatrics, Public Health

Keywords: concussions, adolescents

\section{Introduction}

Mild traumatic brain injury, also known as concussion, is common in children, with sports and recreation as a leading cause [1-2]. More than 150,000 school-aged children present to the 
emergency department (ED) each year for concussion and concussion-related injuries in the United States [3]. The number of ED visits and hospitalizations for concussions is also increasing [4]. Given the widespread prevalence of this public health problem, understanding of concussions - why, how, and where they can occur, as well as what should be done about them is extremely important. The authors sought to assess the knowledge, awareness, and attitudes regarding concussion among middle school children.

\section{Materials And Methods}

This was a pre- and post-survey design with a 45 -minute didactic educational session in between the pre-test and post-test, designed to assess the effectiveness of such an intervention on the knowledge and attitudes towards concussion or mild traumatic brain injury (TBI), as well as baseline characteristics. The survey instrument collected demographics, information on students' safety habits, and their knowledge and attitudes as they relate to concussion or mild TBI. The educational intervention involved a Powerpoint ${ }^{\circledR}$ (Microsoft Corp., Redmond, WA) presentation developed by the authors that covered the epidemiology, pathophysiology, and clinical outcomes after a concussion, as well behaviors more likely to result in a concussion. The Powerpoint presentation was followed by a review and distribution of printed materials from the Centers for Disease Control's Heads Up campaign. The setting was a public middle school in Alachua County, Florida, USA. Students from the eighth grade were recruited to participate as part of the author's (TSS) science project. A letter explaining the project was sent home with each student, and students could participate after the student and their parent or legal guardian signed the informed consent. The surveys were anonymous, but they were paired so that it was possible to correlate the pre- and post-test answers to the respondents. The surveys were collected in a single sitting at school after regular school hours. The middle school science department approved the project in accordance with local ethics.

Statistical analyses were performed using JMP 14.0 for the Macintosh (SAS Institute Inc., Cary, NC). Descriptive statistics were used to report cohort characteristics, participation in sports, and demographics. For the questions relating to knowledge and attitudes about concussion, percentages were reported for each response in the pre- and post- intervention categories. The two-proportion $\mathrm{Z}$ test was used to study differences in pre- and post-test answers.

\section{Results}

At baseline, $43 \%$ of the students never wore a helmet when riding a bicycle or skateboard (Figure 1). Only 68\% knew that the state had a helmet law for children. After the educational intervention, $15 \%$ said they would still not wear a helmet $(p=0.0228)$, and $27 \%$ learned that Florida does indeed have a helmet law for children $(\mathrm{p}=0.0074)$ (Table 1).

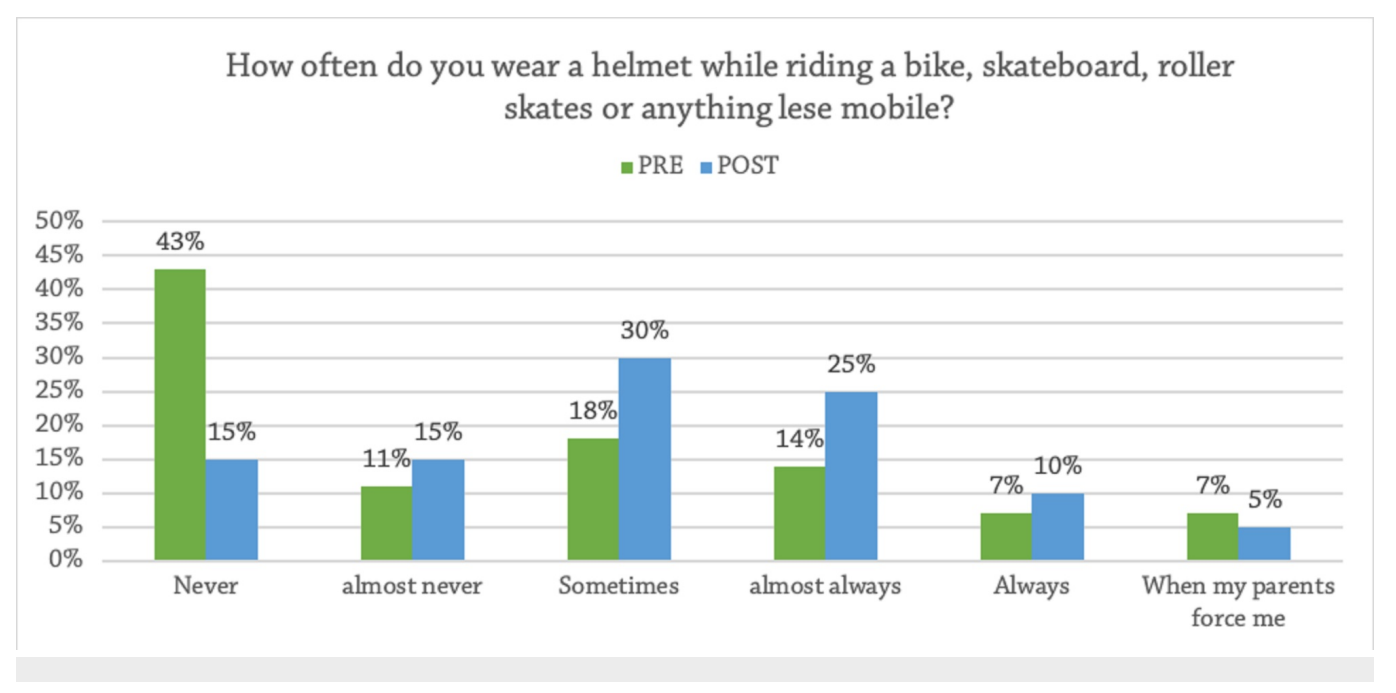




\section{Cureus}

FIGURE 1: Frequency of Helmet Use

Does Florida have a helmet law?

$\begin{array}{lcccc} & \text { PRE } & \text { POST } & \text { p-value } & 95 \% \mathrm{Cl} \\ \text { YES } & 68 \% & 95 \% & & 0.0726 \text { to } 0.4674 \\ \text { NO } & 32 \% & 5 \% & 0.0074 & \end{array}$

\section{TABLE 1: Knowledge of Local Helmet Laws}

$\mathrm{Cl}$ : confidence interval

Eighty-six percent of the students reported wearing their seatbelt always or almost always. This number rose to $100 \%$ on the post-survey (Figure 2). Students reported that their mothers (vs. fathers) were significantly more likely to wear seatbelts ( $p=0.05,95 \%$ CI 0.0036 to 0.5036 )

(Table 2). Knowledge of seatbelt laws for drivers and passengers is reported in Figure 3.

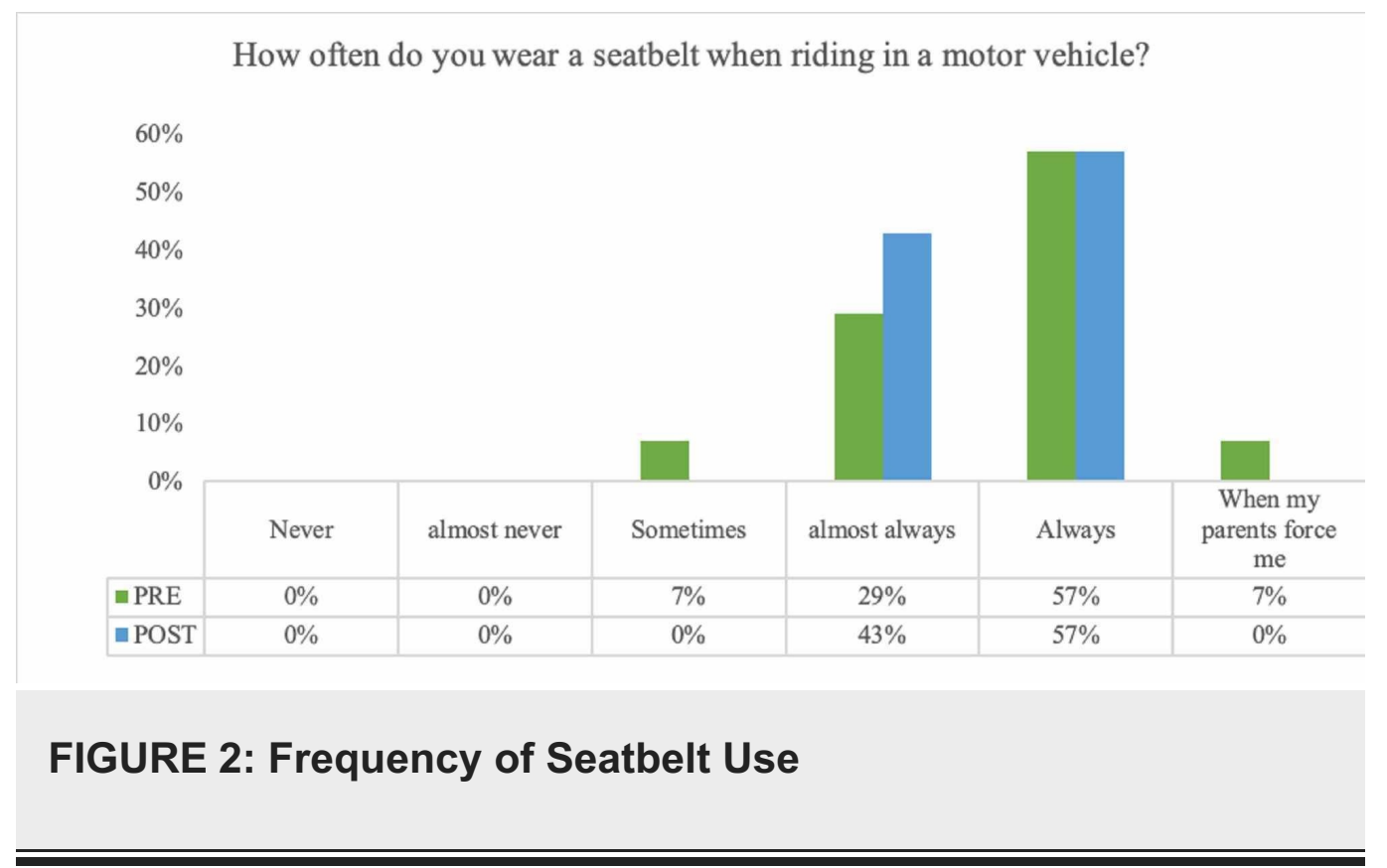




\section{Cureus}

\section{How often does your parent wear a seatbelt?}

$\begin{array}{lllll} & \text { Mother } & \text { Father } & \text { p-value } & 95 \% \mathrm{Cl} \\ \text { Never } & 0 \% & 4 \% & \mathrm{NS} & \mathrm{NS} \\ \text { Almost never } & 4 \% & 4 \% & \mathrm{NS} & \mathrm{NS} \\ \text { Sometimes } & 7 \% & 14 \% & 0.0036 \text { to } 0.5036 \\ \text { Almost always } & 14 \% & 18 \% & 0.05 & \end{array}$

\section{TABLE 2: Frequency of Seatbelt Use in Parents}

Cl: confidence interval; N/A: not applicable; NS: non-significant

Correct knowledge of Florida seatbelt law

incorrect

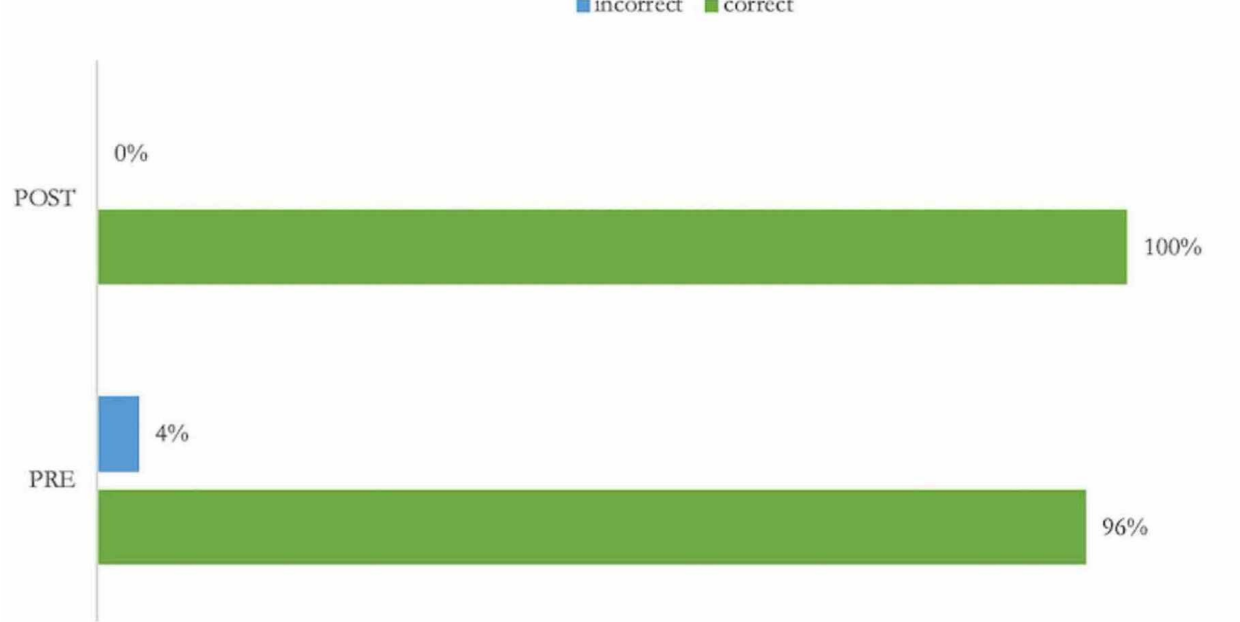

FIGURE 3: Correct Knowledge of Local Seatbelt Laws for the Driver and Front Seat Passenger

Participants' responses to their use of safety accessories and the importance of safety to them were mixed (Figures 4-5). Participants were significantly more likely to feel they had good TBI knowledge (Table 3) after the intervention ( $\mathrm{p}=0.0005$, 95\% CI 0.1937 to 0.6863 ), and that the didactic lectures changed the way they thought about safety ( $p=0.0034,95 \%$ CI 0.1025 to $0.5175)$. 


\section{Cureus}

On a scale from 1-5 how much do you NOT wear your safety accessories just to be "cool"?

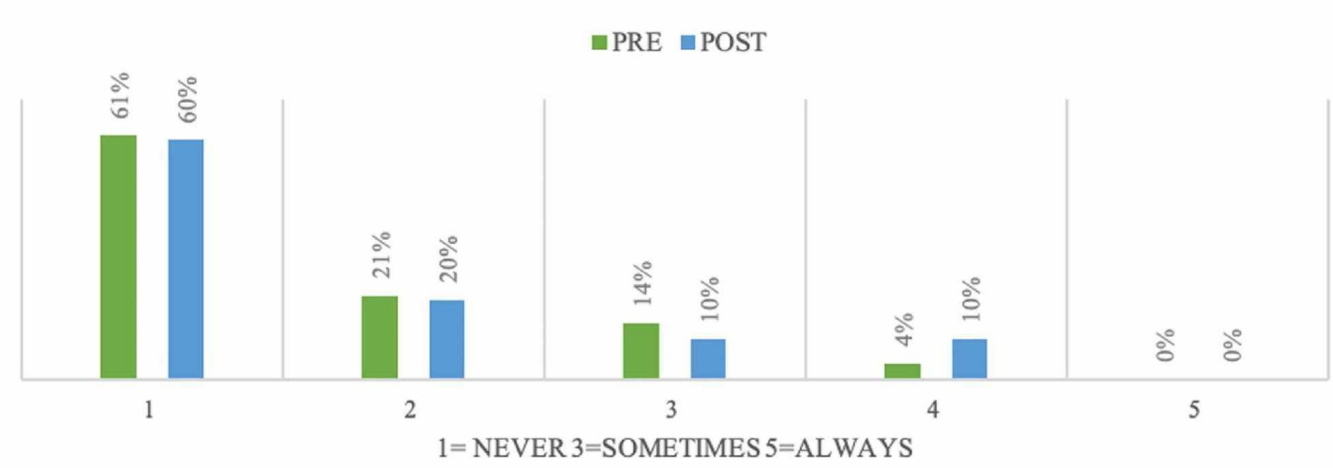

FIGURE 4: Use of Safety Accessories

On a scale from 1-5 how important is safety to you?

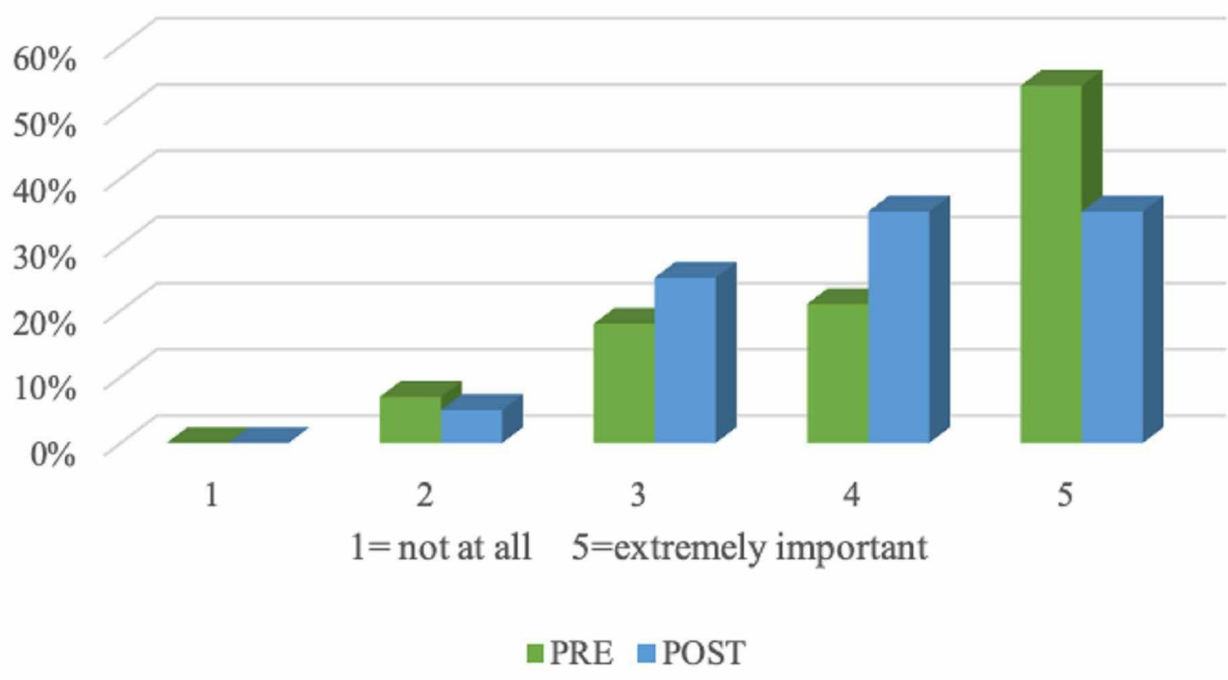

FIGURE 5: Importance of Safety 


\section{Cureus}

On a scale from 1 to 5 , how much do you think safety lectures and talks change the way you think about safety?

$\begin{array}{lllll} & \text { PRE } & \text { POST } & \text { p-value } & 95 \% \mathrm{Cl} \\ 1 & 29 \% & 5 \% & 0.015 & -0.4333 \text { to } 0.0467 \\ 2 & 39 \% & 35 \% & \text { NS } & \text { n/a } \\ 3 & 29 \% & 15 \% & \text { NS } & \text { n/a } \\ 4 & 4 \% & 35 \% & .0060 & 0.0887 \text { to } 0.5313 \\ 5 & 0 \% & 10 \% & \text { NS } & \text { n/a }\end{array}$

\section{TABLE 3: Impact of Safety Lectures}

Cl: confidence interval; N/A: not applicable; NS: non-significant

\section{Discussion}

The literature affirms the knowledge gap demonstrated in this study. One study that examined parents' knowledge of pediatric concussions in school and on the sports field noted that $51 \%$ of respondents were unaware that head trauma was more serious in children, $44 \%$ of respondents did not know there were medical guidelines to return to play, and 35\% did not know that repeated head trauma could cause dementia [5]. A study of high school athletes $(n=496)$ found that older child age $(p=0.01)$ and female sex $(p=0.03)$ were associated with better knowledge of pediatric concussion [6]. Another article concluded that among student-athletes, athletic trainers were the ones most likely to refer the student to medical help if they suspected a concussion (50.8\%). School nurses followed closely (37.0\%). Among non-student athletes, guidance counselors were the first ones to respond to suspected concussions (46.5\%), followed closely again by school nurses (43.2\%) [7].

Another study examined the knowledge gap among coaches and athletic trainers [8] and found that knowledge of symptoms was very good (over $90 \%$ of the $n=916$ cohort correctly identified five or more of the eight most common symptoms of concussion); however, knowledge of youth susceptibility and repeat concussion was lacking. The study found that less than $40 \%$ of the cohort recognized that younger athletes were more susceptible to concussion, and a mere $25 \%$ of the subjects knew that subsequent to sustaining a concussion, a repeated head injury can be up to five times as likely to occur. Beyond the knowledge of baseline information about concussions, studies have also examined whether knowledge alone results in behavior change. An anonymous survey of college students $(n=262)$ (an older cohort than those in the current study) found that $43 \%$ of those with a history of concussion reported that they had knowingly hidden symptoms of a concussion to stay in a game and $22 \%$ of athletes overall indicated that they would be unlikely or very unlikely to report concussion symptoms to a coach or athletic trainer in the future. These data suggest that there may be a substantial degree of underreporting of concussion among collegiate athletes, despite most acknowledging that they have been formally educated about the risks of concussion [9].

Although many studies have examined this knowledge gap and severity of concussion management in student-athletes and coaches of these athletes, there has been substantially less research on a combined cohort of athletes and non-athletes as part of a junior high cohort, which is what this study examined. We found that pre-presentation knowledge of all aspects of 
concussion (symptoms, outcomes, mortality, etc.) among students was relatively Gaussian, with no substantial increase or decrease in the knowledge gap between athletes and nonathletes. After the clinical presentation that included mortality and the neurodynamics of a concussion, all students experienced an increase in knowledge and awareness of concussion. Although the mean knowledge level increased almost by a factor of two, a follow-up of students examining safety habits (such as wearing a helmet and seatbelt) was not statistically significant, and no association between knowledge of concussion and changing in safety habits was found. Closing the knowledge gap through clinical and epidemiological presentations of concussion in athletics will hopefully increase the percentage of self-reported and selfdiagnosed concussions, thus decreasing the morbidity of concussion and improving outcomes of students all across the nation.

\section{Conclusions}

There still exists a knowledge gap when it comes to pediatric concussion. Expanding awareness is important in order to bolster safety measures among adolescents. Education regarding concussion in the form of school curriculum may help in this regard.

\section{Additional Information}

\section{Disclosures}

Human subjects: Consent was obtained by all participants in this study. N/A issued approval N/A. This project was approved by the Science Department at Howard Bishop Middle School in Alachua County, Florida. Animal subjects: All authors have confirmed that this study did not involve animal subjects or tissue. Conflicts of interest: In compliance with the ICMJE uniform disclosure form, all authors declare the following: Payment/services info: All authors have declared that no financial support was received from any organization for the submitted work. Financial relationships: All authors have declared that they have no financial relationships at present or within the previous three years with any organizations that might have an interest in the submitted work. Other relationships: All authors have declared that there are no other relationships or activities that could appear to have influenced the submitted work.

\section{Acknowledgements}

These data were presented in research abstract form at the American Academy of Neurology Annual Meeting on April 6, 2015 in Washington, DC. This research was supported (in whole or in part) by HCA Healthcare and/or an HCA Healthcare-affiliated entity. The views expressed in this publication represent those of the author(s) and do not necessarily represent the official views of HCA Healthcare or any of its affiliated entities.

\section{References}

1. Nonfatal Traumatic Brain Injuries Related to Sports and Recreation Activities Among Persons Aged $\leqslant 19$ Years --- United States, 2001--2009. (2011). Accessed: April 17, 2019: http://www.cdc.gov/mmwr/preview/mmwrhtml/mm6039a1.htm?s_cid.

2. Gordon KE, Dooley JM, Wood EP: Descriptive epidemiology of concussion. Pediatr Neurol. 2006, 34:376-78. 10.1016/j.pediatrneurol.2005.09.007

3. Rose SC, Weber KD, Collen JB, Heyer GL: The diagnosis and management of concussion in children and adolescents. Pediatr Neurol. 2015, 53:108-18. 10.1016/j.pediatrneurol.2015.04.003

4. Yang J, Phillips G, Xiang H, Allareddy V, Heiden E, Peek-Asa C: Hospitalisations for sportrelated concussions in US children aged 5 to 18 years during 2000-2004. Br J Sports Med. 2008, 42:664-69. 10.1136/bjsm.2007.040923

5. LaBond V, Barber KR, Golden IJ: Sports-related head injuries in students: parents' knowledge, attitudes, and perceptions. NASN Sch Nurse. 2014, 29:194-99. 10.1177/1942602X14527827 


\section{Cureus}

6. Kurowski B, Pomerantz WJ, Schaiper C, Gittelman MA: Factors that influence concussion knowledge and self reported attitudes in high school athletes. J Trauma Acute Care Surg. 2014, 77:S12-17. 10.1097/TA.0000000000000316

7. Heyer GL, Weber KD, Rose SC, Perkins SQ, Schmittauer CE: High school principal's resources, knowledge, and practices regarding the returning student with concussion. J Pediatr. 2015, 166:594-9.e7. 10.1016/j.jpeds.2014.09.038

8. White PE, Newton JD, Makdissi M, et al.: Knowledge about sports-related concussion: is the message getting through to coaches and trainers?. Br J Sports Med. 2014, 48:119-24.

10.1136/bjsports-2013-092785

9. Torres DM, Galetta KM, Phillips HW, et al.: Sports-related concussion: anonymous survey of a collegiate cohort. Neurol Clin Pract. 2013, 3:279-87. 10.1212/CPJ.0b013e3182a1ba22 